\title{
Consumo
}

\section{Esses roquero não curte: performance de gosto e fãs de música no Unidos Contra o Rock do Facebook ${ }^{1}$}

These rockers don't like: taste as performance and music fans at Facebook fanpage United Against Rock

ADRIANA AMARAL

Professora do Programa de Pós-Graduação em Ciências da Comunicação da Unisinos.

<adriamaral@unisinos.br>

CAMILA MONTEIRO

Mestranda em Ciências da Comunicação pelo Programa de Pós-Graduação da Unisinos.

<camilafrancomonteiro@gmail.com>

\section{RESUMO}

O presente artigo trata do debate sobre o gosto e suas manifestações nos sites de redes sociais. Discutimos a noção de performance de gosto (Hennion, 2007, 2010) como uma relação experiencial entre sujeitos, música e as materialidades da tecnologias. A partir da contextualização das discussões sobre o gosto e os fãs de musica, descrevemos e caracterizamos de forma exploratória algumas formas empíricas dessas manifestações, tomando como exemplo a fanpage Unidos Contra o Rock do Facebook. Dentre as observações iniciais destacamos o amálgama entre as disputas simbólicas e distinções sociais (Bourdieu, 2008) no embate entre os gêneros rock e funk carioca; os elementos de capital subcultural (Thornton, 1996) e a sociabilidade ora lúdica ora combativa de fãs, antifãs, haters e trolls. Tais aspectos constituem modos de performatização do gosto musical atuando nas mediações entre a escuta e os gêneros musicais no contexto da cultura contemporânea.

Palavras-chave: Performance de Gosto; Fãs de Musica; Facebook.

\section{ABSTRACT}

The present paper explores the debate about taste and its manifestations in social network websites. We discuss the notion of taste as performance (Hennion, 2007, 2010) working as an experiential relation between subjects, music and the materiality of technologies. Based on the contextualization of discussions about taste and music fans, we describe and characterize some empirical shapes/ways of these manifestations, setting/using facebook Brazilian fanpage "Unidos Contra o Rock" (United Against Rock) as an example. Amongst initial observations we highlight the amalgam between symbolic disputes and social distinctions (Bourdieu, 2008) in the clash dividing music genres such as rock and funk carioca; elements of subcultural capital (Thornton, 1996) and sociability, sometimes ludic or combative between fans, antifans, haters and trolls. Such aspects form different manners of creating a performance of musical taste, acting in the mediations between listening and musical genres in the context of contemporary culture.

Keywords: Taste Performance; Music fans; Facebook. 
7 odos os dias ao abrirmos a página inicial/timeline do Facebook nos deparamos com

L compartilhamento e postagem de conteúdos relativos ao gosto pessoal de cada um dos perfis que acompanhamos. São videoclipes via YouTube, músicas pelo SoundCloud, fotos e imagens de artistas dos álbuns pessoais ou dos perfis específicos de alguma banda ou ator, links com textos, posts de blogs ou matérias sobre os mesmos. Michel Teló, Adele e Wando, entre tantos outros, são escutados, ironizados, compartilhados, curtidos de forma frenética e com discussões polarizadas entre os que amam e odeiam tais artistas; conversações e críticas que desvelam aspectos cotidianos a respeito do consumo de produtos culturais mediados pelos objetos técnicos.

São muitas as possibilidades de investigação e hipóteses acerca dessas práticas. Nesse artigo, optamos por tratar do estatuto da discussão sobre o gosto na internet, trazendo a noção de performance de gosto (Hennion, 2007, 2010) como uma relação experencial entre os sujeitos, a música e as materialidades tecnológicas. Além disso, ela também pode ser pensada como uma forma possível de abordagem para observarmos as manifestações de gosto nas redes digitais, especialmente nas mobilizações geradas pelos embates entre fãs e antifãs, trolls e haters. Nosso foco nesse estudo teórico-exploratório recai sobre como tais debates a respeito do gosto musical, uma vez compartilhados através dos sites de redes sociais, e em especial no Facebook, desempenham uma série de apropriações criativas ou imaginativas (Aguilera, Adell e Borges, 2010, p. 40) ora individuais, ora coletivas que atuam nas mediações entre os modos de escuta, as sociabilidades e os gêneros musicais no contexto da cibercultura.

Num primeiro momento, discutiremos algumas abordagens sobre o gosto, assim como o desenvolvimento teórico desse debate nos ambientes mediados pelo computador. A prática de compartilhamento de conteúdos e conversações relativas a gêneros musicais permite que a disputa simbólica sobre os gostos revele facetas comportamentais e sociais por parte de seus apreciadores. Assim, fãs e antifãs 
argumentam, xingam, classificam e até se organizam para demonstrar apoio ou descontentamento em relação a um determinado artista ou para colocá-lo em uma visibilidade ainda maior, sendo uma parte central nesse processo. Partimos inicialmente desse debate sobre o gosto e sua performatização para procedermos a uma observação piloto das manifestações e relações que se estabelecem enquanto disputas entre diferentes gêneros musicais na página Unidos Contra o Rock ${ }^{2}$ (UCR) do Facebook. Essa fanpage de entretenimento apresentou-se como um exemplo interessante no qual os elementos relativos à performatização do gosto aparecem intensamente.

\section{Gostar ou não gostar? Questão teórica}

Discussões sobre o gosto ou sobre como ele é constituído/adquirido têm ocupado um lugar entre os campos da estética, filosofia e sociologia, entre outros. O trabalho seminal de Bourdieu (2008) indica que o gosto é um elemento primordial para identidade de classe e vice-versa, uma vez que o gosto classifica o próprio classificador. $\mathrm{O}$ autor postula que há uma determinação socioeconômica circunstancial refletida em diferentes níveis econômicos e no capital cultural nos quais residem relações sociais de pertencimento e exclusão embutidas no ato de classificar um gosto como inferior ou superior.

O senso de distinção, disposição adquirida, motivada pela necessidade obscura do instinto, afirma-se não tanto nos manifestos e manifestações positivas da certeza de si, mas nas inumeráveis escolhas estilísticas ou temáticas que, tendo como princípio a preocupação de marcar a diferença, excluem todas as formas (consideradas em determinado momento como) inferiores da atividade intelectual (ou artística), objetos vulgares, referencias indignas, modos de exposição."

(Bourdieu, 2008, p. 460) 
Diversos autores ampliam e/ou criticam a análise de Bourdieu em sua sociologia do gosto. Shustermann (1998, p. 103) afirma que, apesar de Bourdieu revelar as lógicas de distinção entre as classes sociais, ele acaba sofrendo do mesmo tipo de preconceito classificatório ao buscar uma estética "autêntica". Ao referir-se a ela entre aspas, "Bourdieu afirma que a assim chamada estética popular não passa de um inverso negativo do qual toda estética autêntica deve se distanciar para afirmar sua legitimidade" (Shustermann, 1998, p. 103).

De acordo com Liu (2007, on-line), “desde Bourdieu, a literatura anglo-americana sobre performance tem minimizado amplamente o determinismo socioeconômico, em vez disso, confiando em bases estéticas"3. Já Thornton (1996), que analisou os gostos dos membros da subcultura clubber no Reino Unido nos anos 90 observou que as normas dominantes entre esses jovens participantes não girava em torno de aspectos socioeconômicos, mas sim do que ela chamou de "capital subcultural"4.

A partir de uma abordagem mais relacionada à materialidade dos objetos e às práticas culturais relacionadas às diferentes formas de escuta mediadas pela miríade de objetos técnicos disponíveis, Hennion $(2007,2010)$ propõe a ideia de performance de gosto. Na concepção do autor, a noção de gosto é cada vez menos simbólica e mais inserida em uma cultura material, mais relacionada à presença do objeto, corporificado, sentido como uma vinculação ${ }^{5}$ afetiva entre sujeitos e objetos.

O gosto não é nem a consequência - automática nem induzida - dos objetos que provocam o gosto por si mesmos, nem uma pura disposição social projetada sobre os objetos ou o simples pretesto de um jogo ritual e coletivo. É um dispositivo reflexivo e instrumentalizado para colocar à prova nossas sensações. Não é um processo mecânico, sempre é 'intencional'."

(Hennion, 2010, p. 28) ${ }^{6}$ 
No presente artigo, abordamos a noção de gosto musical enquanto performance, que envolve uma série de práticas, sensações, objetos e comportamentos. A discussão levantada por Hennion $(2007,2010)$ aproxima-se do que entendemos por apropriação criativa da cultura material. A proposta metodológica de investigação da pragmática do gosto $^{7}$ do autor inclui uma abordagem etnográfica que leva em consideração os comportamentos dos fãs - no caso dele, os amantes de música erudita - em relação aos seus ambientes (o trem, o escritório, a casa) e objetos de escuta (o CD player, o $i$ Pod).

Além disso, o autor não rejeita os "determinismos socioeconômicos" de Bourdieu (2008), nem o "determinismo subcultural" evocado por Thornton (1996), mas sim os incorpora como parte da pragmática do gosto, no qual ele também incorpora os amantes de música como importantes agentes para a compreensão dos modos de escuta atuais, em um "determinismo de fã", pois "os fãs ${ }^{8}$ não lutam contra os determinismos. Entre todos os determinismos possíveis, eles elegem um" (Hennion, 2010, p. 28) ${ }^{9}$.

Outra questão interessante incorporada pela ideia de performance de gosto trata do vínculo entre os sujeitos e os objetos técnicos como plataformas, ferramentas, os espaços e as práticas. Essa ideia aparece nos textos do autor ainda de forma não delimitada e pouco elucidada - suas conceituações por vezes soam um tanto diáfanas, ensaísticas e epifânicas - e dialoga tanto com a abordagem das materialidades da comunicação ${ }^{10}$, aqui especificamente aplicadas aos estudos sobre a escuta ou sound studies; tanto quanto com a abordagem que observa as tecnologias como artefatos culturais ${ }^{11}$. Assim, ela é uma concepção possível para interpretarmos os fenômenos de gosto e sua publicização através dos sites de redes sociais. 


\section{a) Gostos musicais performatizados através das tecnologias}

A constituição do gosto em seus aspectos teóricos vem sendo discutida por vários autores. No entanto, as apropriações, discussões e as mediações realizadas através das plataformas de redes sociais ainda são pouco debatidas. Liu, Maes e Davenport (2006) e Liu (2007), assim como Hennion (2007, 2010), também utilizam o termo performance de gosto em suas análises quanti-qualitativas de perfis do MySpace. Nesses dois casos, o uso do termo é devedor da concepção de performatização do self encontrada em Goffmann (1959). Hennion (2007) retoma a noção gofmanniana - embora sem anunciá-la - e a desenvolve numa direção relacionada ao gosto e as práticas de consumo.

Sob condições que precisam ser estabelecidas (a ideia não é transferir para a música 'mesma' o que uma interpretação social exógena não supre mais), são as capacidades mais gerais da música que produzem estados individuais e coletivos - ou, em outras palavras, a hipótese da performatividade condicionada da música ${ }^{12}$ - que pode nos permitir a formulação de implicações de pesquisa sobre o gosto musical, conforme compreendido em uma variedade de formas, por uma ampla diversidade de amantes da música, como uma prática rica e inventiva que simultaneamente recoloca a música e os seus praticantes in situ, de acordo com as necessidades e com os mais variados meios, recursos, dispositivos e cerimoniais disponíveis."

(Hennion, 2007, p. 03) $)^{13}$

Amaral (2007); Amaral e Aquino (2009) discutiram respectivamente as classificações de gêneros musicais através do social tagging e os tipos de práticas de 
folksonomia dos usuários da plataforma de recomendação musical Last.fm. Baym e Ledbetter (2009) tratam dos aspectos identitários que o compartilhamento de playlists nos perfis do Last.fm propicia, e, no entanto atentam que a sociabilidade nesse ambiente é composta por laços fracos, uma vez os contatos sociais se redistribuem e migram para outras ferramentas de acordo com o avanço das discussões.

Sá (2009) aborda as diferentes concepções a respeito dos sistemas de recomendação musical inferindo a importância dos agentes mediadores, sejam eles humanos ou máquinas, nas disputas simbólicas sobre o gosto que ocorrem nessas plataformas. Essa reconfiguração dos espaços e das experiências da escuta musical indicado pela autora tem nos fãs de música seus personagens centrais.

Nós olhamos aqui, sobre todo o ato de compartilhar música, um instrumento já antigo da sociabilidade cultural, desde os primórdios que se valoriza sua notável importância para entender os mecanismos de negociação de sentido e da identidade por parte dos fãs de música e de outros participantes nos atos musicais."

(Aguilera, Adell e Borges, 2010, p. 37) ${ }^{14}$

No intuito de vislumbrar os fluxos dessas disputas e suas demarcações na e através da internet, torna-se metodologicamente importante delinearmos algumas definições sobre fãs e antifãs, bem como a relação dos mesmos com os gêneros musicais. Essas definições encontram-se em construção a partir da literatura específica e do seu confronto com exemplos empíricos coletados por Monteiro (2011) em sua pesquisa sobre fãs e antifãs da banda Restart e na análise das mobilizações dos fãs dessa mesma 
banda para atingir os tópicos mais comentados do Twitter (Trends) realizada por Recuero, Amaral e Monteiro (2012).

\section{b) As disputas apaixonadas entre fãs e antifãs sobre gostos e gêneros musicais}

Eu entenderia fandom, nãofandom e antifandom como uma dimensão completamente diferente do que se considera como oposto, dominante, ou leituras negociadas. Assim como não podemos compreender verdadeiramente um conceito como gênero sem interrogar tanto 'masculinidade' e 'feminilidade', nós não conseguiremos compreender verdadeiramente como o afeto acontece de forma generalizada, ou até mesmo como os fandoms trabalham especificamente, até explorarmos um pouco mais os antifandoms ${ }^{15}$."

(Gray, 2010, online)

Pioneiros nos estudos de fãs, Tulloch \& Jenkins (1995) ao estudarem o fandom ${ }^{16}$ da série da televisão britânica Doctor Who, no fim dos anos 80 , início dos 90, classificaram fãs e apreciadores em dois diferentes grupos: os primeiros são extremamente ativos, tem poder e influência social, cultural e interpretam signos de formas diferentes do que os demais. Os apreciadores, embora se mostrem interessados, não têm o mesmo nível de engajamento, e mais do que isso, não são identificados como figuras presentes e participativas do fandom. Ser fã é muito mais do que participar, é trocar, partilhar, seja através de listas de discussão, tradução de músicas, criticas pesadas ou na criação de material (fanfics, fanvideos, fanzines). O que Jenkins (2008) define 
como cultura participativa e Baym (2010), cultura da dádiva, traduz o fã atual, cuja capacidade de produção, reprodução, criação e circulação é cada vez maior. Graças à internet, os fandoms tornaram-se globalizados e visados, principalmente pelos grandes conglomerados midiáticos.

No entanto, em meio a compartilhamentos, mobilizações e generosidade, os fandoms são, "paixão cercada por disputas" (Jenkins, 1992). O autor, cuja influência dos Estudos Culturais se mostra evidente ao discutir hegemonia e sistemas de circulação já comentava em 1992 a coexistência de fãs e não fãs:

Fãs veem a comunidade como uma oposição consciente ao mundo comum, habitado pelos 'não fãs', tentando construir estruturas sociais mais receptivas às diferenças individuais, onde exista mais espaço aos desejos particulares e que sejam democráticas e comunitárias em suas operações."

(Jenkins, 1992, p. 213)

Da mesma forma que existem diferenças claras entre fãs e apreciadores, antifãs e não fãs possuem características distintas. Gray (2003) classifica os antifãs como um grupo de pessoas com sentimentos fortes contra algum texto ou gênero, os considerando estúpidos ou bobagens. Contudo, o autor reitera que a organização e a visibilidade desses antifandoms podem ser tão fortes quanto às do fandom. Podemos perceber isso claramente com os grupos de haters (odiadores) ${ }^{17}$ da banda Restart (Monteiro, 2011), onde grupos criam sites, vídeos, contas no Twitter para falar mal desses artistas. 
Fãs e antifãs são dois lados da mesma moeda. A fama de um determinado artista sempre causa o efeito de criação de haters. Onde quer que haja um fã, haverá um antifã ou hater, é parte da dinâmica. No Brasil, os torcedores/fãs de futebol são um exemplo sintomático. A diferença é que com o crescimento da popularização da internet no país, ambos os grupos (fãs e antifãs) tornam-se mais visíveis, bem como as possibilidades de arquivamento dessas discussões para pesquisas ou para objetivos mercadológicos. As apropriações e usos dessas redes como o Twitter ou Facebook amplificam esse tipo de engajamento."

(Amaral, 2012, online)

Theodoropolou (2007, p. 316), cujos objetos de estudo são dois times de futebol, diferencia antifandoms esportivos, musicais e televisivos, e traz uma característica que destaca a importante participação dos antifãs dentro dos fandoms: "o investimento emocional nos antifandoms é importante na construção da identidade do fã". Apesar da autora diferenciar os fandoms, em razão dos grupos musicais não serem bipolarizados como o futebol (a autora estudou os fandoms esportivos aqui-inimigos Olympiakos e Panathinaikos, o que seria equivalente ao Gre-Nal/Fla-Flu), existem diversos casos na música, onde fandoms são "rivais", a exemplo de Oasis e Blur ou das cantoras pop Britney Spears e Christina Aguilera ${ }^{18}$, etc.

Outro aspecto abordado pela autora é o fato de que no esporte, por mais insultos, canções ofensivas e brigas que ocorram, entre os times parece existir mais respeito. O time considera o outro bom o suficiente para ser insultado, é uma ameaça. Já em relação aos fandoms e antifandoms musicais, isso não parece existir. Em casos como o que observamos sobre a banda Restart, os antifãs odeiam a banda porque a consideram colorida demais, rock de menos e basicamente ruim (Monteiro, 2011, p. 4). A ameaça 
está no fato de a banda ocupar paradas de sucesso, ter fãs engajados que a colocam nos assuntos do momento no Twitter, vendagem de discos, mas não existe respeito pela banda, nem pelos seus fãs, mas sim uma desqualificação dos mesmos. Além disso, há a questão central em torno do gênero musical com suas normas e regras. De acordo com o argumento desses antifãs, uma banda como Restart não poderia ser classificada como rock, pois elementos sonoros como volume, tom, peso e velocidade caracterizariam o gênero e não aparecem nesses artistas.

Uma característica que chama atenção é a vida curta que os antifandoms têm, conforme observados através da abordagem quanti-qualitativa adotada por Recuero, Amaral e Monteiro (2012). Os odiadores da banda clamam que os fãs são temporários, mas eles próprios também não perpetuam o ódio. Os fãs por sua vez, além de serem amigos uns dos outros (proporcionando laços mais fortes e mais intensos), têm o objetivo de promover shows, aparições, singles ou qualquer outra novidade relacionada à banda. Em poucos minutos são capazes de se organizarem e colocarem uma hashtag nos assuntos mais importantes do momento.

Apesar das definições de Gray (2003) e do trabalho empírico de Theodoropoulou (2007) serem importantes para os estudos sobre a cultura dos fãs, é preciso lembrar que a temática dos antifãs ainda foi pouco abordada pela literatura específica e, consequentemente, há dificuldade em torno das definições. Sendo assim, as discussões ${ }^{19}$ dos próprios grupos de fãs em torno das definições de termos como antifã, hater e troll ${ }^{20}$, se mostram também como fontes importantes para a construção de futuras categorizações.

Uma das características dessas discussões entre fãs é a diferenciação entre haters e trolls. Ao observar exploratoriamente alguns fóruns aleatórios sobre fãs e fandoms ${ }^{21}$, constatou-se que na perspectiva dos fãs em geral, os haters são pessoas que odeiam algo e "ponto final". Eles odeiam o tipo de música, o corte de cabelo, o rosto, o jeito, entre outras características. Já o troll, nesse contexto, é aquele que não necessariamente 
odeia algo, mas tem prazer de ver a briga entre fãs e antifãs acontecer. Em alguns casos o troll finge que é antifã só para ver confusão. Ele chama os haters para briga. Joga fãs e haters uns contra os outros por diversão participando como manipulador, gerando discórdia e decepção nas comunidades online, conforme já indicava Donath (1998, p. 14). As definições sobre trolls na internet (como em Donath, 1998; Fontanella, 2010, 2011) tendem a associá-lo ao anonimato. No entanto, percebe-se a partir das observações empíricas que atualmente existem muitas derivações nas quais os trolls não são exclusivamente anônimos e o ato de "trollar" ora ajuda a viralizar determinados memes ou produtos culturais; ora são brincadeiras com alguma personalidade ou perfil.

Ainda através da voz dos fãs, o hater, corroborando a ideia de Gray (2003), tem conhecimento para odiar algo e é antifã, por que, antes de mais nada, ele é fã de outra coisa. O comportamento contrário a algo é gerado como um sistema de defesa ao que ama. Já o troll, odeia como hobby, se diverte, ri. Segundo Fontanella (2007), o aspecto lúdico e humorístico acompanhou o desenvolvimento da internet, das primeiras BBS e listas de discussão aos sites de redes sociais e aplicativos.

Há uma questão identitária que se revela através dessas guerras simbólicas no campo discursivo que estão relacionadas com o engajamento de fãs e antifãs com a informação e sua interpretação e ressignificação de produtos comunicacionais. O não fã simplesmente não liga para um determinado artista ou franquia e, por conta disso, sua identidade se dá através da exclusão. Já o antifã constrói sua identidade (ou parte dela) pelo seu gosto "diferenciado" ou através da estratégia de mostrar as incoerências e malgosto do discurso dos fãs daquele produto (por exemplo, a saga Crepúsculo ou o cantor Michel Teló). O antifã também assiste, analisa, anota, avalia, classifica e gera significado sobre o conteúdo e produz conteúdo tanto quanto o fã, porém seu objetivo é diverso. Elelela quer 'provar' o quanto o produto ou artista ou os seus fãs são ruins. Os antifãs demostram sua declaração de gosto para construir o seu não pertencimento aquele grupo/geração, etc."

(Amaral, 2012, online) 
A exploração dessas categorias, que emergiram a partir do próprio campo, precisam de aprofundamento em trabalhos futuros. Por hora, elas nos auxiliam como instrumentos operatórios para observar a performatização de gosto na página UCR.

\section{A performatização dos gostos no Facebook}

Para tratar do exemplo escolhido, primeiro retomaremos brevemente a relação entre a performance e gêneros musicais, e por fim traçaremos algumas considerações iniciais sobre as práticas que ocorrem nesse meio a partir das noções sobre performance de gosto e fãs.

\section{a) Performance e gêneros musicais}

Frith (1996) explica que os gêneros servem basicamente para organizar os processos de venda. Ele, e Negus (1999) afirmam que ao discutirmos gêneros, três perguntas devem ser feitas: onde essa música se encaixa? O som dela lembra o que? E por fim, quem vai comprar? Frith lembra que o gênero é uma forma de definir a música no mercado, ou o mercado na música (p. 76). Ele ainda compara o mercado fonográfico com editores e escritores, frisando a importância da classificação dos gêneros para a definição do público, uma vez que encaixado em um gênero, espera-se que o artista aja de determinada maneira. Afinal, o que as pessoas que escutam aquele gênero vão pensar do som da banda?

Dialogando com Frith (1996), Janotti Jr. e Pires (2011) afirmam que os gêneros ordenam o mercado musical e direcionam o público. Ele lembra que os gêneros envolvem regras econômicas, através do direcionamento e apropriação cultural; regras semióticas onde estratégias de produção de sentido são relacionadas aos produtos musicais e por fim as regras técnicas e formais, envolvendo a produção e recepção 
musical no sentido estrito, conectadas ao conhecimento musical (2011, p. 7). Ainda na discussão sobre gêneros, Frith (1996) explica que essas classificações são necessárias tanto para os processos de criação e escuta das músicas, como para as vendagens, frisando que os gêneros musicais são construídos e precisam ser compreendidos dentro do processo cultural e comercial.

Janotti Jr. (2006) diz que a musica popular massiva não é só produção, mas está diretamente ligada ao modo em que tanto o público como os músicos/produtores se apropriam do produto. A produção do sentido da música está atrelada também à utilização da internet, bem como relacionadas à performance, à manifestação corporal, à voz, ao timbre, à altura, reverberação, ritmo e cenário (2006, p. 9). Segundo o autor, eles estão conectados com diversos cenários presentes de forma virtual nos gêneros musicais, e materializados nas canções.

A performance não é considerada apenas como sendo produzida pelo artista, mas também aquela que é produzida pelos fãs. Ao proteger e defender seus ídolos, os fãs de certa forma criam personas, geralmente para não parecer deslocado, ou um "mau exemplo de fã". É possível entender a performance do fã, quando por exemplo a banda se apresenta em um programa e alguma coisa dá errado. Um tropeço, uma nota errada, uma roupa fora de lugar. Os fãs, apesar de reconhecerem o erro, não só defendem o artista, como fazem de tudo para que os cantores saibam que eles estão felizes, independente do que aconteceu. Se algum antifã/troll fala mal, os fãs rapidamente atuam nas redes sociais para defender os ídolos.

b) Considerações sobre o Unidos contra o Rock

A fanpage de entretenimento Unidos $U C R^{22}$ tem como descrição a seguinte frase: 


\section{ESSA PÁGINA É EXCLUSIVAMENTE VOLTADA PARA}

CONTEÚDO DE HUMOR ÁCIDO. Ela não tem propósito de ofender ninguém, se você não gosta dela, de ctrl+w ou chute seu estabilizador, não te obrigamos a ler nem ver as imagens. Nós levamos a internet a sério."

É uma página de humor cujo ponto central é ironizar e debochar dos elementos característicos do rock, de seus artistas e fãs. Uma boa parte das postagens compara o gênero rock com gêneros habitualmente desprezados por seus fãs como o funk carioca e o axé, entre outros. A foto do perfil é uma montagem misturando as cabeças dos integrantes do Nirvana com a turma do programa infantil do dinossauro Barney (Fig. 1). A página também possui um blog hospedado no Tumblr ${ }^{23}$, no qual muitas das imagens são replicadas.

Figura 1 - Página de entrada da fanpage UCR - 14/01/2012

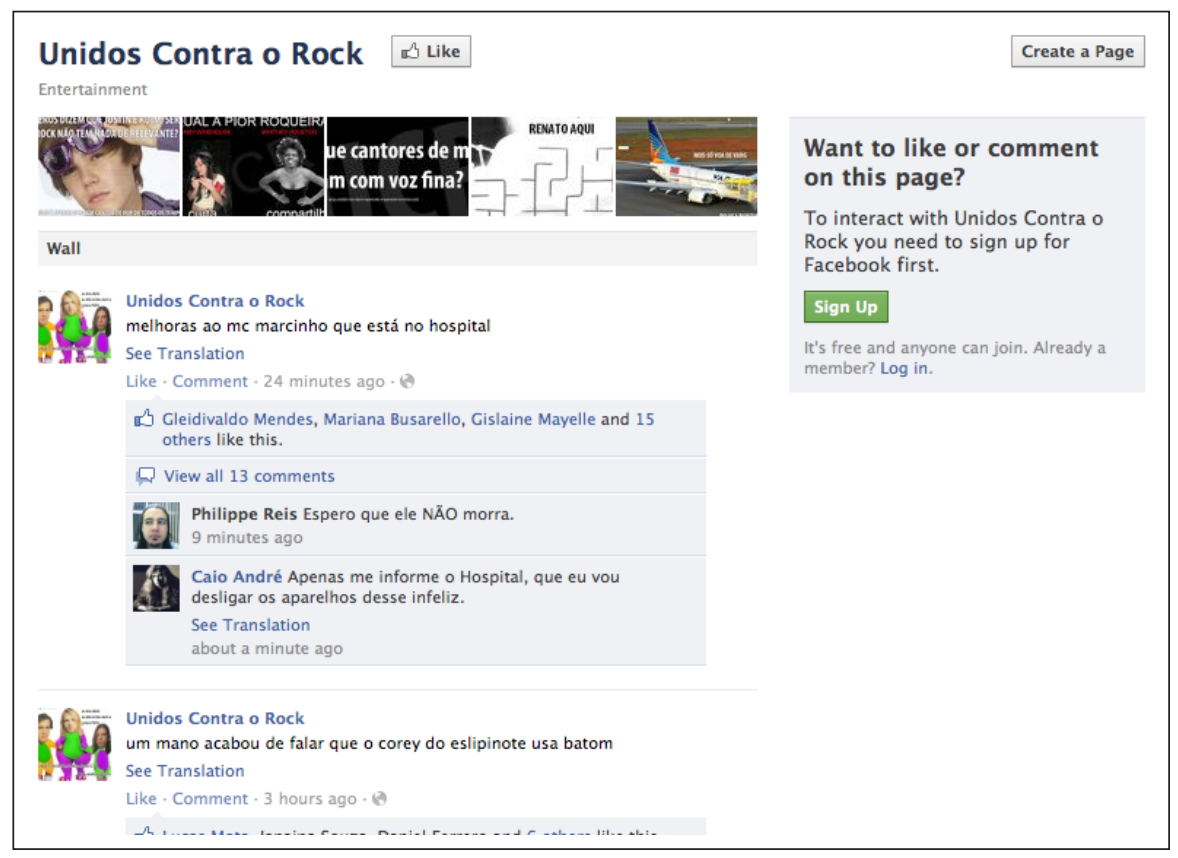


As considerações a respeito desse exemplo foram obtidas a partir de uma primeira aproximação com o mesmo, e sua escolha foi por intensidade, ou seja, detectando "elementos nos quais a informação é mais densa ou fácil de verificar" (Fragoso, Recuero e Amaral, 2011, p. 79). A princípio ela nos chamou atenção por ser compartilhada por diversas pessoas presentes em nossos perfis - notadamente pessoas cujo gosto musical é o rock - no próprio Facebook $(F B)$. A opção por essa fanpage aconteceu de forma intencional. Além disso, consideramos quatro características que se destacaram na amostra:

1) A apropriação criativa reconfigura uma performance de gosto musical a partir da materialidade própria de um meio de compartilhamento de conteúdos musicais sob desígnios dos fãs de um determinado gênero musical, levando em consideração agentes, recursos e dispositivos disponíveis (Hennion, 2007). A fanpage UCR apresenta uma série de recursos de interatividade e compartilhamento de conteúdos, além das possibilidades de monitoramento dos posts mais acessados através de métricas disponíveis. Algumas para todos que acessam como o número de curtir ou de comentários e compartilhamentos de cada página; assim como a estatísticas de acesso - disponível apenas para quem a criou.

2) O nome das páginas criadas dentro do $F B$ para grupos, empresas, instituições, etc. é Fan Page (página de fã) remetendo à importância dessa prática e desses atores sociais como nos informa o próprio site. "Desde Novembro de 2007, bandas, clubes esportivos, artistas, filmes, marcas, ONGs e negócios tem utilizado as Páginas como presenças livres e customizáveis no Facebook [...] um perfil público que deixa os usuários conectados com aquilo pelo qual eles se importam" 24 . 
3) O irônico embate entre diferentes gêneros musicais mostrando características e regras facilmente reconhecidas dos mesmos ou os subvertendo, normalmente através de uma imagem acompanhada de um texto comparativo ${ }^{25}$ entre um roqueiro e um funkeiro conforme a Fig. 2, por exemplo.

\section{DIFERENÇA ENTRE FUNK E ROCK}
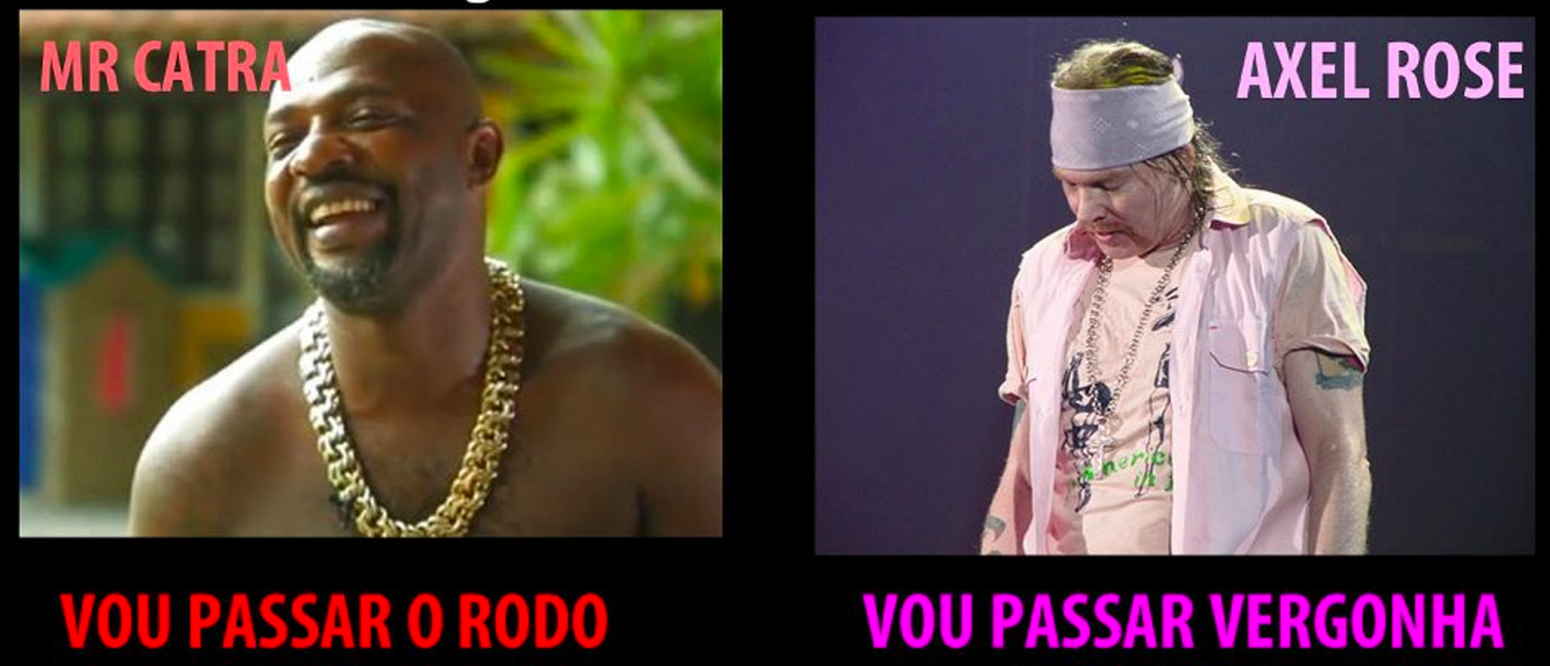

www.UnidosContra.com.br

fb.com/UnidosContraoRock V2

Figura 2 - Mr. Catra (funk carioca) $\times$ Axl Rose (hard rock) 
4) O grande número de comentários nas postagens e a intensidade dos mesmos, incluindo as performatizações de gosto; os preconceitos e legitimações de gosto a partir de embate entre classes sociais diferentes; e as disputas entre os fãs, antifãs, trolls e haters dos artistas e/ou gêneros criticados conforme podemos observar no exemplo sobre a banda Megadeth (Fig. 3) e nos comentários (Fig. 4 e Fig. 5).

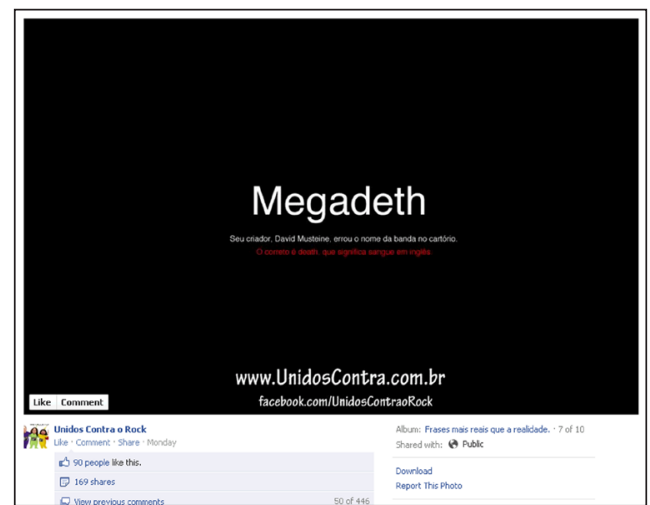

Figura 3 - Postagem sobre a banda Megadeth

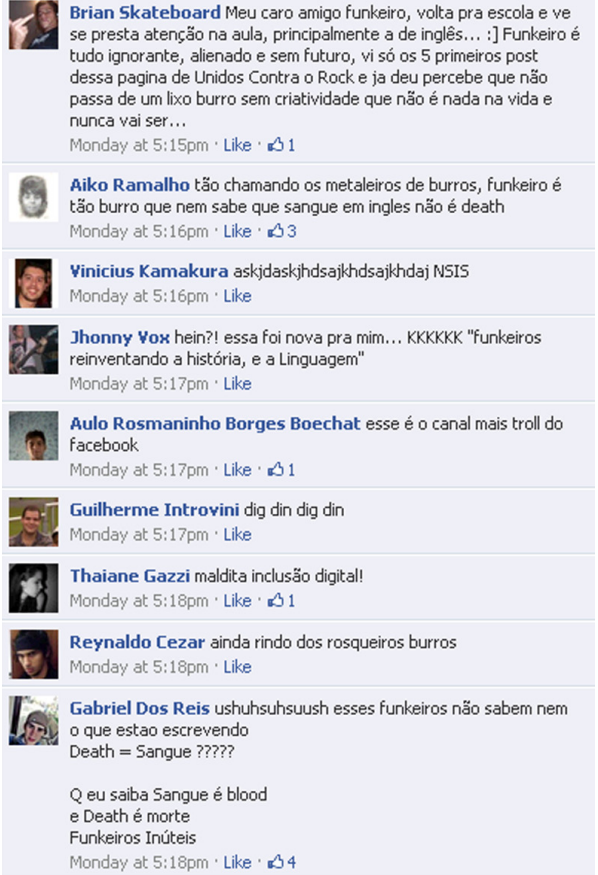

Figura 4 - Comentários

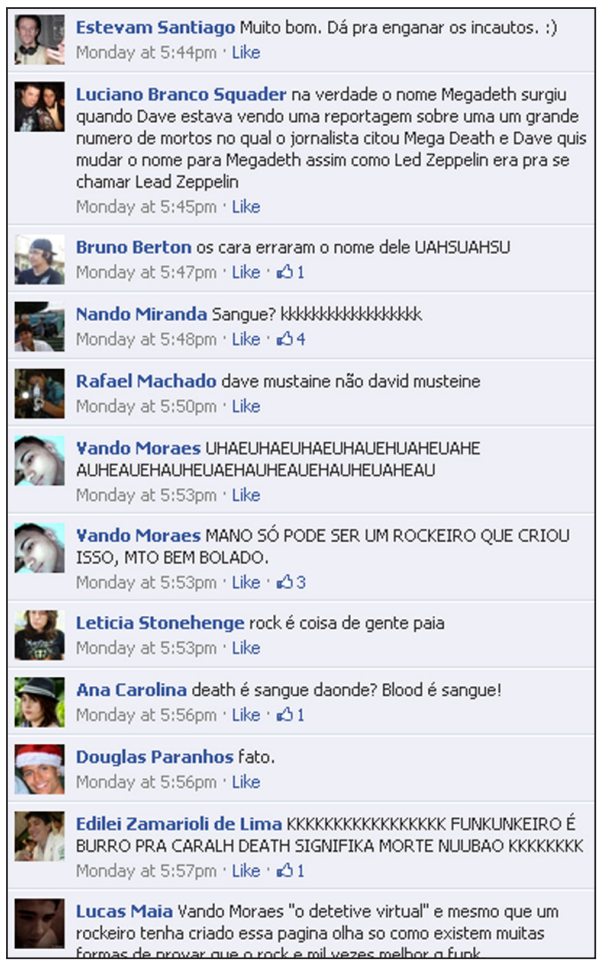

Figura 5 - Comentários 
A postagem original (13/01/2012) possui 169 compartilhamentos e mais de 90 comentários. Podemos observar as manifestações de preconceito dos usuários T.G ("maldita inclusão digital") e B.S ("funkeiro é tudo ignorante, alienado e sem futuro"); a indicação da existência lúdica da trollagem no comentário de A.B. ("esse é o canal mais troll do Facebook"); e a reação de fãs e antifãs que defendem e criticam ora o gênero ora a banda, como L.M. ("mesmo que um roqueiro tenha criado essa página olha como existem mil maneiras de provar que rock é melhor do que funk"); L.S. ("Na verdade o nome Megadeth surgiu quando Dave estava vendo uma reportagem").

A partir dessa aproximação inicial com a página do UCR como exemplo, percebemos questões importantes para o debate sobre o gosto nos sites de redes sociais. Há uma combinação de categorias que se desvelam em uma primeira mirada sobre a fanpage.

O mais importante deles é compreender a performatização de gosto musical (Hennion, 2007; 2010) como uma dimensão central nas práticas de escuta da cultura contemporânea. Através do próprio ato de apropriação criativa da materialidade dessa ferramenta, nas postagens de quem gerencia o perfil, ao disponibilizar e permitir a discussão entre fãs, não fãs e antifãs de rock e funk carioca, sobretudo e de quem ali comenta participando desse circuito. Essa performatização do gosto envolve ainda três outros aspectos que cabem ser destacados:

a) os embates entre amantes do rock $\times$ amantes do funk que muitas vezes revelam seus preconceitos sobre o gosto das diferentes classes sociais ${ }^{26}$ (comentários como "funkeiro é sem futuro e favelado" e "rockeiro é guri de apartamento, filhinho da mamãe"27) a eles associados. Essa ideia filia-se à noção de distinção e disputa simbólica defendida na sociologia do gosto de Bourdieu (2008); 
b) aspectos da lógica subcultural também aparecem, sobretudo nas postagens relativas ao subgênero Black Metal (Fig. 6), demonstrando um capital subcultural (Thornton, 1996) por parte de quem a postou, uma vez que a compreensão da piada vai além do visual ou da sonoridade da musica e implica conhecer aspectos históricos de determinada banda ou cantor. Nesse caso específico é parte do domínio comum do conhecimento sobre o Black Metal saber que o vocalista da banda norueguesa Burzum, Varg Virkenes assassinou o guitarrista da banda Mayhem a facadas em 1993;

c) por fim, destacamos a complexa relação entre fãs, antifãs, não fãs, trolls e haters dentro desse espaço de sociabilidade. As definições

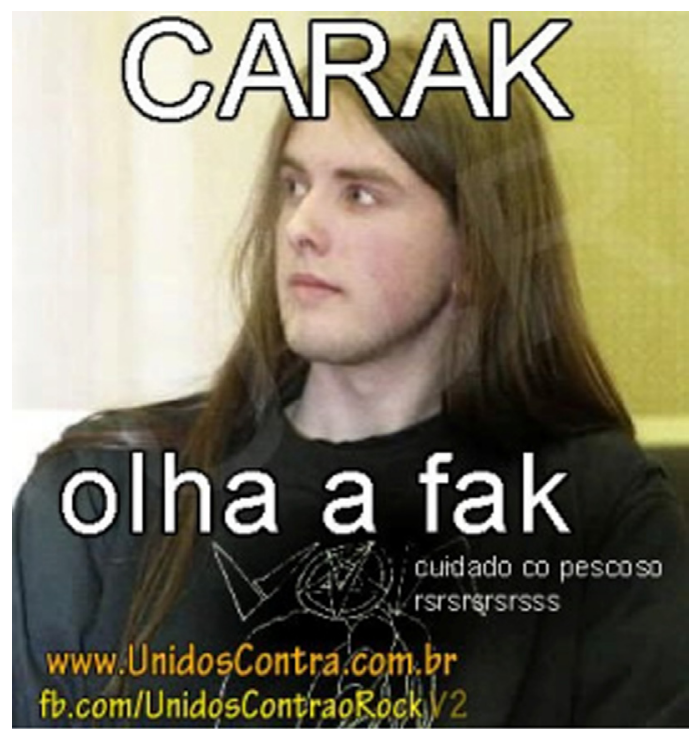

Figura 6 - Varg Vikernes apresentadas pelos autores são frágeis e nos parece que a cada inserção a campo para observações de tais práticas, os papéis desempenhados por esses atores sociais se complementam e se opõem, entre outras combinações possíveis. No entanto, continuam atuando de forma decisiva nas mediações e entre a escuta e as discussões sobre o gosto através das plataformas digitais.

\section{Considerações finais}

O presente artigo explorou o debate sobre o gosto e suas manifestações nos sites de redes sociais. Contextualizamos a questão do gosto, partindo de uma tradição que vêm da sociologia do gosto (Bourdieu, 2008) rumo a uma performatização do gosto 
proposta por Hennion $(2007,2010)$. Observamos como essas manifestações, sobretudo a respeito da música podem ser estudadas em uma abordagem que considere os artefatos culturais tecnológicos e os fãs de música como parte do próprio objeto, sobretudo nos ambientes de sociabilidade propiciados pelas plataformas digitais (Sá, 2009, Liu, 2007). As apropriações criativas e as práticas culturais que se desenvolvem em torno da música são parte desse entorno e nos dão pistas sobre os comportamentos relativos às formas de escuta na cultura contemporânea. Para tal empreendimento analítico nesses contextos é preciso que o pesquisador

se concentre nos gestos, nos objetos, nos corpos, nos meios, nos dispositivos e nas relações envolvidas. O gosto é um comportamento. Reproduzir, escutar, gravar, fazer com que os outros escutem música... todas essas atividades vem a ser algo mais que a realização de um gosto que "já existia". Ele se redefine por completo durante a ação e o resultado é, em parte, incerto. Assim, a vinculação dos fãs e a forma de fazer as coisas se combinam, formam subjetividades e tem uma história que não pode ser reduzida às das obras."

(Hennion, 2010, p. 25) ${ }^{28}$

Em nossa proposta, essas subjetividades e vinculações foram observadas a partir de uma tentativa de delineamento de características dos fãs e antifãs que também performatizam seu gosto de forma ao mesmo tempo pública e privada no Facebook. Tomando como ponto de partida os estudos de fãs e observando as suas próprias vozes em ambientes online, procuramos debater diferenças e semelhanças, continuidades e rupturas nas práticas dos fãs, não fãs, antifãs, trolls e haters de música. 
As definições ainda em construção que emergiram da observação do empírico, assim como as abordagens sobre o gosto, constituíram também categorias para considerações iniciais sobre o exemplo da fanpage UCR, na qual percebemos o atravessamento de várias formas de performatização do gosto: socioeconômica e de distinção; de manifestações de capital subcultural nas postagens ou comentários expressos no formato de duelo entre o funk carioca e o rock como gêneros supostamente antagônicos e não-conciliáveis e do humor como forma de desvelar esses debates.

Restaram-nos ainda diversos questionamentos que nos impulsionam a dar continuidade nas pesquisas sobre esse complexo e multifacetado tema. A reflexão a partir de um caso ilustrativo como esse, pode vir a ser observada como um dos padrões que permeia as formas de sociabilidade nos sites de redes sociais no que tange a performatização do gosto nos ajudando a compreender de forma mais ampla alguns comportamentos, subjetividades e até mesmo processos de viralização de conteúdos e materiais que se encontrem nesse âmbito.

\section{REFERÊNCIAS}

AMARAL, Adriana. Categorização dos Gêneros musicais na Internet. Para uma etnografia virtual das práticas comunicacionais na paltaforma social Last.fm. In: FREIRE FILHO, João, HERSCHMANN, Michael (Org.). Novos rumos da cultura da mídia. Indústrias, produtos e audiências. Rio de Janeiro: Mauad, 2007. v. 01, pp. 227-242. com/73kedr8s.

Dialogando sobre mobilizações de fãs e antifãs. Blog adriamaral.com. Disponível em: <http://tinyurl.

. Práticas de Fansourcing. Estratégias de mobilização e curadoria musical nas plataformas musicais. In: SÁ, Simone (Org). Rumos da cultura da música. Porto Alegre: Sulina, 2010.

AMARAL, Adriana, AQUINO, Maria Clara. Eu recomendo... e etiqueto. Práticas de folksonomia dos usuários do Last.fm. Revista Líbero, ano XII, n. 24, pp. 117-129, dez. 2009.

AGUILERA, Miguel de; ADELL, Joan Elies; BORGES, Eddy. Apropiaciones imaginativas de la musica en los nuevos escenarios comunicativos, Comunicar - Revista Científica de Educomunicacion, v. XVII, n. 34, 2010. 
BAYM, Nancy. Personal connections in the digital age. Cambridge: Polity Press, 2010.

BAYM, Nancy; LEDBETTER, Andrew. Tunes that Bind?: Predicting Friendship Strength in a Music-Based Social Network. Information, Communication \& Society, v. 12, n. 3, 2009.

BOURDIEU, Pierre. A distinção. Crítica social do julgamento. São Paulo: EDUSP, 2008.

DONATH, Judith. Identity and deception in the virtual community. In: SMITH, M.; KOLLOCK, P. (Eds.). Communities in Cyberspace. London: Routledge. 1998.

FELINTO, Erick; PEREIRA, Vinícius Andrade. A vida dos objetos: um diálogo com o pensamento da materialidade da comunicação. Contemporânea, Salvador, v. 3, n. 1, pp. 75-94, 2005.

FONTANELLA, Fernando. Nós somos anonymous: anonimato, trolls e a subcultura dos imageboards. In: XXXIII Congresso da Intercom, 2010, Caxias do Sul-RS.

FRAGOSO, Suely; RECUERO, Raquel; AMARAL, Adriana. Métodos de pesquisa para Internet. Porto Alegre: Sulina, 2011.

FRITH, Simon. Performing Rites: on the value of popular music. Cambridge/Massachusett: Havard University Press, 1996.

GOFFMANN, Erving. The presentation of self in everyday life. Garden City, NY: Doubleday, 1959.

GRAY, Jonathan. Antifans and paratexts. An Interview with Jonathan Gray. (Part One). In: JENKINS, Henry. Confessions of an Aca-Fan, Weblog, 2010. Disponível em: <http://henryjenkins.org/2010/03/on_antifans_and_ paratexts_an.html>. Acesso em: 10 fev. 2012.

. New audiences, new textualities: antifans and non-fans. In: International Journal of Cultural Studies, London, pp. 64-81, 2003.

HENNION, Antoine. Gustos Musicales: de una sociologia de la mediacion a una pragmática del gusto. Comunicar - Revista Científica de Educomunicacion, n. 34, v. XVII, pp. 25-33, 2010.

. Music Lovers. Taste as performance. Theory, Culture E Society, v. 18, n. 5, Dec. 2007.

JANOTTI JR, Jeder. Mídia, música popular massiva e gêneros musicais: a produção de sentido no formato canção a partir de suas condições de produção e reconhecimento. In: XV Encontro da Compós, 2006, Bauru-SP.

JANOTTI JR., Jeder; PIRES, Victor de Almeida. Entre os afetos e os mercados culturais: as cenas musicais como formas de mediatização dos consumos musicais. In: Dez anos a mil: mídia e música popular massiva em tempos de internet. Porto Alegre: Simplíssimo, 2011. pp. 8-22.

JENKINS, Henry. Cultura da convergência. São Paulo: Aleph, 2008. 
LIU, Hugo. Social network profiles as taste performances. Journal of Computer-Mediated Communication, v. 13, n. 1, article 13, 2007. Disponível em: <http://jcmc.indiana.edu/vol13/issue1/liu.html>.

LIU, Hugo; MAES, Pattie; DAVENPORT, Glorianna. Unraveling the taste fabric of social networks. International Journal on Semantic Web and Information Systems, v. 2, n. 1, pp. 42-71, 2006.

MONTEIRO, Camila. Fã-mília \#happyrock: "recomeço” em cores. I Simpósio em Tecnologias Digitais e Sociabilidade, 2011, Salvador-BA. Disponível em: <http://migre.me/7dt0V>.

NEGUS, Keith. Music genres and corporate cultures. Londres e Nova Iorque: Routledge, 1999.

RECUERO, Raquel; AMARAL, Adriana; MONTEIRO, Camila. \#Restartthebestidols. Fandoms, trending topics and social capital in twitter. Paper submitted to IWSM, Ireland, 2012.

SÁ, Simone Pereira de. Se você gosta de Madonna também vai gostar de Britney! Ou não? Gêneros, gosto e disputa simbólica nos sistemas de recomendação musical. XVIII Encontro da Compós, 2009, Belo Horizonte-MG. Disponível em: <http://www.compos.org.br/>. Acesso em: 05 ago. 2011.

SHUSTERMAN, Richard. Vivendo a arte. O pensamento pragmatista e a estética popular. São Paulo: Editora 34, 1998.

THEODOROPOULOU, Vivi. The antifan within the fan - awe and envy in sport fandom. In: GRAY, Jonathan; SANDVOSS, Cornel; HARRINGTON, C. Lee. Fandom: identities and communities in a mediated world. New York: New York University Press, 2007.

THORNTON, Sarah. Club cultures. Music, media and subcultural capital. London: Wesleyan University Press, 1996.

TULLOCH, John; JENKINS, Henry (Eds.). Science fiction audiences: Watching Doctor Who and Star Trek. Londres: Routledge, 1995.

\section{NOTAS}

1 Essa é uma versão modificada e ampliada do trabalho de mesmo nome apresentado no Grupo de Trabalho Comunicação e Cibercultura do XXI Encontro da Compós, na Universidade Federal de Juiz de Fora, Juiz de Fora, de 12 a 15 de junho de 2012. O presente trabalho tem o apoio do CNPq.

$2<$ http://www.facebook.com/unidoscontraorock>.

3 Tradução das autoras: "anglo-American scholarship on taste since Bourdieu has largely downplayed socioeconomic determinism, instead relying upon aesthetic groundings" (Liu, 2007, online).

4 Para maiores discussões sobre a apropriação que Thronton fez das noções de capital social para capital subcultural, ver Amaral (2010). 
5 Hennion (2010, p. 26) comenta que prefere utilizar o termo "vinculação", uma vez que a carga simbólica do termo gosto está muito, relacionado à estética e à sociologia. "El gusto constituye una práctica corporal, colectiva e instrumentada, regulada por métodos discutidos sin cesar, orientados en torno a la percepción apropiada de efectos inciertos. Es por ello que preferimos hablar de «vinculaciones»".

6 Tradução das autoras: "El gusto no es ni la consecuencia-automática ni inducida-de los objetos que provocan el gusto por sí mismos, ni una pura disposición social proyectada sobre los objetos o el simple pretexto de un juego ritual y colectivo. Es un dispositivo reflexivo e instrumentado para poner a prueba nuestras sensaciones. No es un proceso mecánico, siempre es «intencionado»" (Hennion, 2010, p. 28).

7 "Salir de una concepción objetivista del gusto, como si no fuera más que la consecuencia de las propiedades físicas de los objetos que motivan el gusto, no implica sustituirla por un análisis social, ritual e interaccionista en el que la creencia en el objeto reemplace el papel de causa primera que antes tenía el objeto en sí" (Hennion, 2010, p. 32).

8 Embora Hennion $(2007,2010)$ se refira ora aos "amantes de musica", ora aos colecionadores e até mesmo músicos amadores que participam de uma cena, tomaremos todos esses termos como sinônimos de fãs.

9 Traduação das autoras "los aficionados no luchan contra los determinismos. Entre todos los determinismos posibles, ellos eligen uno" (Hennion, 2010, p. 28).

${ }^{10}$ Ver Felinto e Pereira (2005), entre outros.

${ }^{11}$ Para um aprofundamento a respeito da abordagem da internet e das tecnologias como artefatos culturais ver o capítulo "Panorama dos Estudos de Internet" de Fragoso, Amaral e Recuero (2011).

12 Grifo das autoras.

${ }^{13}$ Tradução das Autoras: "Under conditions that need to be established (the idea is not to transfer to music 'itself' what exogenous social interpretation no longer supplies), it is the more general capacities of music to produce individual and collective states - or, in other words, the hypothesis of conditioned performativity of music - which can allows us to formulate the implications of research on musical taste, as understood in a variety of ways, by widely diverse music lovers, as a rich and inventive practice that simultaneously recomposes music and its practitioners in situ, according to the needs and with the various mediums, resources, devices and ceremonials available" (Hennion, 2007, p.03).

14 Tradução das autoras: "Nos fijamos aquí, sobre todo, en el acto de compartir música, un instrumento ya antiguo de la sociabilidad cultural, del que hace ya tiempo que se valora su notable importancia para entender los mecanismos de negociación del sentido y de la identidad por parte de los fans, de los aficionados a la música y de otros participantes en los actos musicales" (Aguilera, Adell e Borges, 2010, p. 37).

15 Tradução das Autoras: "I'd see fandom, non-fandom, and antifandom as a completely different dimension from oppositional, dominant, or negotiated readings. So just as we can't truly understand a concept like gender without interrogating both "masculinity" and "femininity," we won't truly get how affect works generally, or even how fandom works specifically, till we explore antifandom a little more." (Gray In: Jenkins, 2010, online).

${ }^{16}$ Coletivo de fã. Fandom, do ponto de vista etimológico, é a junção das palavras fan (fã em inglês) e do sufixo de kingdom (reino, em inglês). 
${ }^{17} \mathrm{O}$ termo haters na internet está relacionado à expressão Haters Gonna Hate (Odiadores vão odiar), um bordão usado para indicar desdém àqueles que falam mal, os odiadores (haters). A expressão, nascida no hip hop norte-americano tornou-se um meme na web, em forma de macros (imagens) de celebridades e animais posando - geralmente caminhando - com expressão de desprezo.

${ }^{18}$ Ver mais em Grandes rivalidades na música, <http://music.ninemsn.com.au/article.aspx?id=296119>.

${ }^{19}$ Como nos exemplos coletados em: <http://tvtropes.org/pmwiki/pmwiki.php/Main/FanHater, http://www. youtube.com/watch?v=D2Q5OplYOyM>. Acesso em: 11 fev. 2012.

20 "Trolls can be costly in several ways. A troll can disrupt the discussion on a newsgroup, disseminate bad advice, and damage the feeling of trust in the newsgroup community. Furthermore, in a group that has become sensitized to trolling - where the rate of deception is high - many honestly naive questions may be quickly rejected as trollings. This can be quite off-putting to the new user who upon venturing a first posting is immediately bombarded with angry accusations" (Donath, 1998, p. 14).

${ }^{21}<$ http://www.darthhater.com/>, <http://forums.televisionwithoutpity.com/index.php?showtopic= 3132336\&st=15>, <http://ohnotheydidnt.livejournal.com/66401770.html>. Acesso em: 11 fev. 2012.

${ }^{22} \mathrm{O}$ levantamento inicial das postagens foi efetuado nas duas primeiras semanas de janeiro de 2012 pelas bolsistas de IC: Camila Armange (UNIBIC), Camila Kehl, (PROBIT - Fapergs), Letícia Petry (Fapergs) e Nassim Natale (CNPq). O levantamento foi feito de forma aleatória a partir de postagens que chamassem a atenção pelas discussões nos comentários ou pela própria imagem/frase postada. Foram coletadas 10 postagens, embora aqui iremos nos restringir a discutir apenas três.

${ }^{23}$ Disponível em: <http://www.unidoscontra.com.br/>. Acesso em: 11 fev. 2012. O Tumblr foi desconsiderado nessa observação inicial porque meramente repetia as imagens do Facebook.

24 Tradução das autoras: "Since November 2007, bands, sports teams, artists, films, brands, non-profits and businesses have been using Pages as free, customizable presences on Facebook (...) a public profile lets users connect to what they care about". Disponível em: <http://www.facebook.com/FacebookPages?sk=info>. Acesso em: 10 jan. 2012.

${ }^{25}$ Essa prática de compartilhamento de macros é bastante comum no FB.

${ }^{26}$ Várias pesquisas sobre o funk carioca debatem a questão do preconceito.

${ }^{27}$ Foram coletadas aleatoriamente um total de 7 postagens em dias diferentes.

${ }^{28}$ Tradução das Autoras: "se concentre en los gestos, los objetos, los cuerpos, los medios, los dispositivos y las relaciones involucradas. El gusto es un comportamiento. Reproducir, escuchar, grabar, hacer que otros escuchen música... todas esas actividades vienen a ser algo más que la realización de un gusto que "ya existía». Todo ello se redefine durante la acción y el resultado es, en parte, incierto. Así, la vinculación de los aficionados y la forma de hacer las cosas se combinan, forman subjetividades y tienen una historia que no se puede reducir a la de las obras" (Hennion, 2010, p. 25). 